\title{
The Impact of Mediation on EFL Learners’ Interpretation
}

\section{Performance}

\author{
Mandana Yousefi ${ }^{1^{*}}$ \\ ${ }^{1}$ Department of English, Quchan Branch, Islamic Azad University, Quchan, Iran \\ *Mandana Yousefi, E-mail: mandanayousefih@gmail.com
}

Received: October 15, 2017 Accepted: November 1, 2017 Online Published: November 28, 2017

doi:10.22158/sll.v1n2p197～URL: http://dx.doi.org/10.22158/sll.v1n2p197

\begin{abstract}
The present study was an attempt to examine the EFL intermediate learners' interpretation performance in translating texts from English to Persian on mediated mode vs. non-mediated one focusing on two different kinds of mediation (clip-mediated vs. peer-mediated mode). It has also investigated the participants' attitudes toward the mediation sessions. It was conducted in an English Language Institute in Bojnourd, Iran. To this aim, a standardized 50-item Nelson English Language Test was administered to 31 participants. Following the homogenizing procedure, the number of the participants decreased to 24. Then, they were randomly divided into two equal groups (control and experimental), each consisting of 12 students. Both groups took part in interpretation classes twice a week, during which the experimental group received mediation as the treatment. The collected data were analyzed by conducting ANCOVA and paired-sample t-test. The results indicated that the EFL learners' interpretation performance was better in mediated mode vs. non-mediated one, and peer-mediation was more effective than clip-mediation in improving their listening performance. In addition, all the participants stated mediation had an effective role in improving their interpretation performance by reducing their anxiety and increasing their self-confidence.
\end{abstract}

\section{Keywords}

dynamic assessment, mediation, interpretation performance

\section{Introduction}

Language is one of the main characteristics and a distinctive feature of mankind among other living things; communication through language is a major requirement for human beings. One aspect of this communication is the relationship among different nations, especially these days that according to McLuhan (1964), the world is uniting in the form of a global village, and translation can be an effective an effective means of facilitating this relationship. Nowadays, as the interaction among nations increases in different fields such as economic, industrial, and political issues, the need for interpretation arises more. Venuti (2000) has stated that "human translation breaks down into (or theories have been 
developed for) interpretation or interpreting (with the further distinction between consecutive and simultaneous) and written translation” (2000, p. 178). In other words, the mode of translation is divided into oral and written forms. As Nord (1997) has stated, interpreting is a form of translation action where the source text is presented in oral form and the result of the translation process is the presentation of the target text to be completed at the moment in relation to the source text. Because of its nature, translation is related to many fields of knowledge such as linguistics, cultural studies, philosophy, sociology, etc. (Munday, 2008).

Listening is undoubtedly one of the essential skills and of course a covert skill to secure a successful interpreting task. Through his Efforts Model, Gile (1992) describes listening as the first of the four main capacities in the course of simultaneous interpretation. It is suggested that the most difficult task amongst native and non-native learners is listening comprehension since the listener must concentrate on a wide variety of sources, both linguistic and non-linguistic, to interpret rapidly what he or she is hearing. During continuous interpreting, advanced listening skill is a prerequisite as it facilitates the note-taking processes (Sundersingh, 2001).

It is evident that one of the most pertinent areas of research concerning interpretation studies is to use new pedagogical trends for teaching and learning interpretation skills (Davies, 2004). Davies also added that the students' specific needs, background knowledge, and learning styles and strategies should be considered to design the pedagogical tools and techniques for the betterment of the students' translation competence and performance. A theory that could be really helpful here is Dynamic Assessment (DA) which is rooted in Vygotsky's (1978) writings on Socio Cultural Theory (SCT) of mind, although Vygotsky, himself, did not use the term DA. "SCT is a system of ideas on the development of the mind. Based on the SCT, learning is a social phenomenon embedded in the cultural context” (Vygotsky, 1978, p. 213).

In Vygotsky's conceptualization, the Zone of Proximal Development (ZPD) is the ideal scenario, and the most prominent definition for ZPD, according to Lantolf and Poehner (2004), is the difference between what an individual can do independently and with no help or mediation and what he or she can do with mediation or others' assistance. They also asserted that the role of mediation is central to ZPD, and the integration of assessment and instruction into a unified activity is the function of DA which is done through appropriate forms of mediation. "DA enables learners to perform beyond their current level of functioning, thereby providing insights into emerging capabilities” (Poehner \& Lantolf, 2013, p. 326). Lantolf and Thorne (2006, as cited in Johnson, 2009) argued that dialogic mediation has a central role in cognitive development:

The relationship of learning to development hinges on dialogic mediation, on the ways in which socialization processes involving the inculcation of concepts through practical-critical activity, mediated by direct adult and/or peer intervention, provide opportunities for the construction of psychological tools through which developing individuals are able to increasingly participate in and produce culturally organized activity (p. 71). 
DA approaches have been used in different areas, whether educational or non-educational (Lidz \& Pena, 1996; Missiuna, 1987; Naeini, 2014; Tzuriel, 2000), and for a wide range of ages, from childhood to adolescence. According to Lauchlan and Carrigan (2013), dynamic assessment sounds an interesting concept and should be practical to the classroom and could add another layer of assessment input regarding the pupil.

According to Torrance and Pryor (1998, as cited in Lantolf \& Poehner, 2004), some teachers react emotionally to support learners' problematic performances, but they are not sensitive to the ZPD and the appropriate mediation required to enhance development. On the other hand, according to the results of some studies (Goh, 2000; Hamouda, 2013; Mayberry, 2006), EFL learners suffer from a multitude overlooked difficulties in listening comprehension. In order to tackle EFL learners' listening comprehension problems, diagnostic assessments such as DA can be helpful for the students. In other words, unification of assessment and instruction in DA procedures can be used as diagnostic evaluations.

In addition, students' poor performance specially in listening comprehension skill has challenged many teachers making them redefine the methods they use in the classroom environment to come up with novel ways of developing students' competence in the language (Sevignon, 1983).

According to Angelelli and Jacobson (2009, p. 3), "research in interpreting just focused traditionally on conference interpreting after the establishment of the International Association of Conference Interpreting in 1953”. Moreover, students majoring in Translation Studies always complain about the difficulty of interpretation courses. Although they know about the positive role of these courses in enhancing their English proficiency; they feel that the course requirements are difficult since they are concerned with listening skills. According to Brown (2001), "listening is the aural medium that gives the way to language acquisition and enables learners to interact in spoken communication” (p. 20). Therefore, students with better listening comprehension skills are able to participate more effectively in class. According to Yousif (2006, p. 35), "different linguistic, conceptual, discourse, acoustic, environmental and psychological variables might hinder effective comprehension”. When surrounded by unresolved obstacles stopping their comprehension, learners have no option except remaining silent if asked to explain the content. Interpretation is a course that should be taught practically and in language laboratories and needs special equipment, but unfortunately, many of these are ignored. The students often have stress in these classes because of their poor listening comprehension skill which has not been paid much attention in high schools in Iran, and accordingly, has resulted in the students' poor performance in interpretation classes. Meanwhile, there is no opportunity for students to experience interpretation practically and act as real interpreters, for example, for a tourist group.

Thus, with regard to the crucial role of dynamic assessment in improving the students' learning, the present study was an attempt to investigate the EFL intermediate learners' interpretation performance in translating texts from English to Persian on mediated mode vs. non-mediated one. It was also the researchers' concern to find any significant difference between the EFL intermediate learners' Published by SCHOLINK INC. 
interpretation performance in translating texts from English to Persian on different kinds of mediation mode (clip-mediated vs. peer-mediated). Finally, this study intended to examine the emotional reaction of the learners toward mediation.

With regard to the purposes of the study, the following research questions were proposed:

1) Is there any significant difference between the EFL intermediate female learners' interpretation performance in translating texts from English into Persian on mediated mode vs. non-mediated one?

2) Is there any significant difference between the EFL intermediate female learners' interpretation performance in translating texts from English into Persian on different kinds of mediation mode (clip-mediated vs. peer-mediated)?

3) How do the students react to mediation emotionally?

\section{Literature Review}

According to Lidz, Dynamic Assessment is defined as "An interaction between an examiner-as-intervener and a learner-as-active participant, which seeks to estimate the degree of modifiability of the learner and the means by which positive changes in cognitive functioning can be induced and maintained” (1987, as cited in Baek \& Kim, 2003, p. 190). The goal of this teaching process is to "modify an individual's cognitive functioning" (Lidz, 1987, p. 122), and to observe subsequent changes in the examinee's learning and use of problem-solving strategies. Lidz (1987, as cited in Flanagan, Mascolo, \& Hardy-Braz, 2009) determines the primary goals of dynamic assessment as (1) to assess a student's ability to understand a problem and to generate a solution, (2) to assess the type and amount of teaching necessary to teach a student a specific principle, (3) to identify any cognitive and non-cognitive factors explaining performance failures, (4) and to determine if such factors can be modified by teaching alone. "It is important to note that dynamic assessment is intended to supplement, not replace, standardized testing. It is a broad assessment approach, rather than a particular test" (Flanagan, Mascolo, \& Hardy-Braz, 2009, par. 16).

Those working within the field of assessment contrast DA approach and the traditional approach to testing. This traditional approach is referred to as Static Assessment (SA). These terms, SA and DA, do not specifically refer to assessments themselves, but rather to the way in which an assessment is administered (Poehner, 2008). Sternberg and Grigorenko (2002) define static assessment as:

An exam in which test items are presented to examinees either one at a time or all at once, and each examinee is asked to respond to these items successively, without feedback or intervention of any kind. At some point in time after the administration of the test is over, each examinee typically receives the only feedback he or she will get: a report on a score or set of scores (p. vii).

According to Flanagan, Mascolo, and Hardy-Braz (2009), dynamic assessment differs from static assessment since the latter involves presenting items to learners without any assistance or intervention for changing or improving their performance in order to award them some points based on the responses provided. Baek and Kim (2003, p. 190) have compared these two approaches as below:

Published by SCHOLINK INC. 
Table 1. Comparisons of Static Assessment versus Dynamic Assessment

\begin{tabular}{ll}
\hline Static Assessment & Dynamic Assessment \\
\hline Examiner is an observer & Examiner is a participant \\
Examinee receives no mediation & Examinee receives mediation \\
Diagnosis $\neq$ Instruction & Diagnosis = Instruction \\
Focused on product & Focused on both process and product \\
Retrospective approach & Prospective approach \\
Decontextualized & Contextualized \\
Low transfer test $\neq$ Authentic task & High transfer test = Authentic task \\
\hline
\end{tabular}

The difference between static and dynamic assessment approaches stems from the paradigms from which they emerged. Static assessment generally involves "passive acceptance, wherein a child's deficits or disabilities are accepted and the environment is modified to help the child work within any identified limitations" (Haywood, 1997; as cited in Haywood \& Lidz, 2007, p. 2). On the other hand, dynamic assessment focuses on active modification of the learner's performance and outwits the effect of their weaknesses by providing them with compensatory strategies (Haywood \& Tzuriel, 1992).

Within the L2 DA framework, learning represents the ability to perform (e.g., to solve a problem or to carry out an instructional task) under mediation of a more skilled other (e.g., parents, teachers, more competent peers, etc.) whereas development is seen as the ability to perform in a different context when the mediation is modified as to become more implicit or removed entirely. The goal of DA is to reveal learners' potential for future development on the intermental plane and to help it develop on the intramental plane through mediator-learner interaction”. As a result, L2 DA understands the mediation as a pedagogical instrument that is intended to bring to light underlying problems and help learners overcome them" (Lantolf \& Poehner, 2008, p. 273).

Many studies have investigated the effect of dynamic assessment on learners' achievement up to now. For example, Tzuriel and Shamir's (2002) research concerning computerized DA is especially important as it establishes the efficacy of computer-assisted mediation. Antón (2003), Kozulin and Garb (2002), and Poehner and Lantolf's (2005) studies exemplify the implementation of interactionist DA into L2 adult learning that include university level students participating in various foreign language assessments. All of these studies demonstrate the ability of DA to distinguish the developmental potential of students. Furthermore, these studies show that DA is valuable in that it provides information that can be used to create an individualized action plan to guide the student's education.

Antón (2003) reports on the utility of a DA procedure in university level students of Spanish as a foreign language. The DA procedure included mediation to observe what students are able to do with the language while being exposed to dialogic teacher-learner interactions. The significance of Antón's study is that it represents an early attempt to diagnose L2 language proficiency by opting for the interactionist 
approach to DA (Poehner, 2005). The results of the study also showed that the inclusion of a mediation-driven DA procedure in the placement test increased the test's ability to differentiate students' writing and speaking skills and to provide the students with more accurate recommendations concerning their particular academic needs.

Gibbons (2003) examined elementary ESL students' ability concerning the appropriate use of an academic register when discussing scientific terms. Gibbon's study also confirmed the power of interaction within the ZPD. The children in this study were able to produce scientific terms through mediation that they were not able to produce while working alone.

Poehner (2005) includes a discussion of the regulatory behaviors of the mediator in his study. Aljaafreh and Lantolf (1994) also created a typology of behaviors that occur within the ZPD. That is, Poehner (2005) and Poehner and Lantolf (2005) elaborated the efficacy of DA as a method of examining the development in terms of language proficiency, as opposed to traditional static assessments. Again, DA is shown to provide a more complete picture of language development.

Alavi, Kaivanpanah, and Shabani (2012) attempted to investigate the applicability of G-DA in identifying the mediate strategies offered by a mediator during his G-DA interactions with a group of L2 learners in the context of listening. Also, there is another study by Shabani (2012) about the usage of DA on L2 learners' reading comprehension, and its focus is to explore the feasibility of Computerized Dynamic Assessment (C-DA) in the context of reading comprehension and, more precisely, the effects of electronically delivering textual and visual scaffolding on L2 readers' comprehension processes.

The research on the effect of dynamic assessment on writing performance by Isavi (2012), applying the regulatory scale offered by Aljaafreh and Lantolf (1994) to Iranian EFL learners’ writing ability, showed that the learners responded differently to the same type of errors they made in the pretest stage after introduction of mediation by the teacher. The regulatory scale which was applied in the intervention stage uncovered the fact that the individual learners had different developmental levels.

In 2012, Kozulin and Grab explored the feasibility of the development and implementation of dynamic assessment of EFL text comprehension of at-risk students. The results of their study indicated that students with a similar performance level demonstrate different and even dramatically different ability to learn and use new text comprehension strategies.

Shabani (2012) tested the feasibility of computerized version of dynamic assessment in the context of L2 reading comprehension. The results showed that electronically delivered mediatory scaffolding can enhance the students' reading comprehension and computer can raise readers' consciousness by directing their attention to the key sections of the text and assisting them to understand the text better.

Although there were several studies examining the effectiveness of DA and mediation in teaching different skills, as far as the researchers have investigated, there has been no study examining the use of different kinds of mediation with regard to teaching interpretation and this study an attempt to fulfill this goal. 


\section{Methodology Participants}

This study benefited from the participation of 31 EFL female learners attending a language institute called English Language School in Bojnourd, Iran (2014). The learners' age range was between 14 and 18, and all were at intermediate level. They were studying English as a foreign language and had already studied New Interchange Series (Richards, Hull, \& Proctor, 2005). In order to make sure in objective terms that the sample was truly homogenous with regard to their English proficiency level, a Nelson English Language Proficiency Test (Fowler \& Coe, 1976) was administered for all the learners and only those whose score fell one standard deviation (6) below and above the mean (30) were examined in the study, reducing the total number of the sample to 24 . Then, they were randomly assigned into two groups, a control group and an experimental one. Since the researchers needed a face-to-face interaction with the participants, the number of the subjects should have been acceptable for Group Dynamic Assessment (GDA) program and hence each group should be consisted of 12 students. Both groups attended 10-session interpretation classes during which the experimental group received mediation as the treatment, but the control group received placebo (no mediation).

\section{Instrumentation}

The instruments used in this research were as follows:

\subsection{Nelson English Language Proficiency Test}

The first instrument used for homogenizing the participants was a standardized Nelson English Language Proficiency Test, Section 300 D (Fowler \& Coe, 1976). It was a 50-item test, including vocabulary and grammar questions. The total score was calculated out of 50, i.e., 1 score for each item, and the time devoted to the test administration was 50 minutes. According to the test scores, the participants were randomly divided into two equal groups, a control group and an experimental group.

\subsection{Interpretation Test}

Materials used for interpretation were two Voice of America (VOA) audio clips whose subject falls into the category of news. The reason for selecting these files was that VOA programs have a normal pace of speaking and clear accent and pronunciation which was reasonable for the level of the participants. Moreover, they have different topics which are interesting for most of people. Some other sources, including ABN Radio, Aljazeera, BBC English News, Bloomberg, CNN, Daystar, Russia today, and TCT, were not suitable, because their pace of speaking was rapid and did not have clear accents.

\subsection{Pre-Test}

At first a pre-test was used to measure the students' knowledge of listening comprehension and translation skills. It included a paragraph containing 14 English sentences which were selected from a VOA audio press clip. All the students in both groups (control and experimental) were required to listen to the sentences and translate them orally while their voices were being recorded by a voice recorder. In fact, this test was a traditional static test. 


\subsection{Quizzes}

During the mediation procedure, twelve quizzes were administered to the experimental group during six sessions; each session consisted of one quiz at the beginning and one at the end to measure the students' progress while being exposed to mediation (clip mediation and peer mediation). Each included an English paragraph with 5 short sentences selected from a VOA audio press clip to be translated into Persian by the participants.

\subsection{Post-Test}

After nine sessions, a posttest consisting of a paragraph with 14 English sentences chosen from a VOA audio press clip was administered to both the experimental and the control groups. All the students in both groups (control and experimental) were required to translate them into Persian orally and their voices were recorded. The results obtained from the pretest and the post-test were analyzed to answer the first two research questions.

\subsection{Semi-Structured Interview}

In order to answer the third research question concerning the participants' reflection and attitudes toward the use of mediation during their listening comprehension performance, the researchers conducted a semi-structured interview constructed (Appendix I) with the students in experimental group. To this aim, 15 questions were written which were revised and modified by three professors. The interviewees answered 12 questions individually during 15-20 minutes while their voices were recorded to be transcribed later.

\section{Procedure}

As mentioned earlier, the purpose of this study was to examine the effect of mediation on EFL learners' interpretation performance. It was framed within the socio-cultural framework to investigate the effectiveness of social interaction between the teacher and the students and among the students themselves in improving the learners' translation ability. To this aim, a standardized 50-item Nelson English Language Test (Fowler \& Coe, 1976) was first administered to 31 participants, so as to select and homogenize the experimental and control groups. They were all female and at intermediate level and have passed the New Interchange Series (Hull \& Proctor, 2005). Following the sampling procedure, the number of the participants reduced to 24 . Then, they were randomly divided into two equal groups (control and experimental), each consisted of 12 students. Both groups took part in interpretation classes twice a week, each session lasted 30 minutes. The classes were held in a language lab equipped with headphones and players.

The first session was the same for both groups. First, a pre-test consisting of an audio VOA clip was administered to all the learners. This clip incorporated audio news with a clear accent and a normal speed. The participants were required to listen and translate the sentences into Persian one by one during 15 minutes while their voices were recorded to be transcribed later. They were allowed to use the Oxford Advanced Learners' Dictionary for checking the spelling of the words or expressions as

Published by SCHOLINK INC. 
well as the Aryan pour English to Persian dictionary for translating the sentences from English into Persian in all sessions.

The second and the third sessions were also the same for both groups, because these two sessions were held with no mediation in order to compare the results of these non-mediated sessions with mediated ones followed. During these sessions, the audio VOA clips were played for the students and they translated 10 sentences while listening. Again, their voices were recorded and transcribed after the sessions.

After the third session, the experimental group received the treatment (i.e., mediation). But the control group continued the usual order of interpretation classes, that is, the audio clips were played and the sentences were translated one by one into Persian by the students.

During the even sessions which were regarded as clip-mediated sessions, the experimental group took a quiz at the beginning of the session including a paragraph that the subjects translated them into Persian individually. Then, another audio VOA clip (mediation) with the same category was played for the students which lasted about one minute and they were asked to translate the sentences in group while using the hints given by the teacher. The hints were ranked from the most implicit hints, for example: listen again or listen carefully, to the most explicit ones, for example: pay attention to the first word. The selection of the type of mediation and its ordering from the most implicit to the most explicit was according to the students' mistakes during the first and second sessions. Finally, another quiz was administered to them including a paragraph and they were required to translate the sentences individually. During these sessions, some sentences were left untranslated, because nobody could translate them.

During the odd sessions which were regarded as peer-mediation sessions, the experimental group took a quiz at the beginning again. Each quiz consisted of a paragraph and the students were required to translate them into Persian individually. After the quiz, the students were asked to translate the sentences left untranslated from the even sessions through peer mediation and by using the hints they received from the teacher as a mediator. Thus, they were asked to give hints or prompts to their peers for the segments that they could not understand from the most implicit to the most explicit ones. The sentences played; some of the subjects had understood the whole sentences, but some had problems and they acted as scaffolding for each other and through interaction with themselves. If the students themselves were not able to help their peers to reply, the teacher gave the subjects some leading hints to help them get the point. Thus, this procedure continued; the participants received clip mediation during the even sessions $\left(4^{\text {th }}, 6^{\text {th }}, \& 8^{\text {th }}\right)$ and peer mediation during the even sessions $\left(3^{\text {rd }}, 5^{\text {th }}, \& 7^{\text {th }}\right)$. Thus, in this way, the data required to answer the second research question were collected.

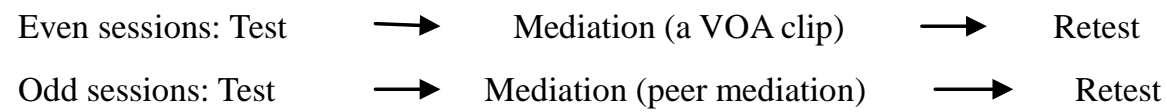

Finally, a post-test consisting of a paragraph containing 14 sentences was administered for all the participants in both the experimental and the control groups during the last session. This test involved Published by SCHOLINK INC. 
the sentences left untranslated during the quizzes, and some other new sentences of a VOA clip. The students had 20 minutes to translate the sentences.

\section{Design}

The purpose of the study was to examine the impact of mediation on the EFL learners' interpretation performance, so the mediation was considered as the independent variable (the treatment), and the learners' interpretation ability was considered as the dependent variable. It adopted both quantitative and qualitative approaches to examine and analyze the data since a mixed method would yield more fruitful and in-depth findings. The design of the quantitative part of this study was quasi-experimental; with pre-test, post-test, control group, experimental group, and treatment:

Control group: Pre-test / 10-session interpretation classes / Post-test

Experimental group: Pre-test / mediation (clip mediation and peer mediation) / Post-test

To answer the first research question, an ANCOVA analysis was conducted. The second research question was answered by using a paired-Sample T-test on the scores of the learners in peer-mediation and clip-mediation sessions.

In order to answer the third research question and to explore the students' reactions towards the effectiveness of mediation and the quality of the hints provided by the teacher, the learners were asked to take part in a semi-structured interview.

\section{Data Analysis}

7.1 ANCOVA Analysis: The Difference between the Learners' Interpretation Performance in Mediated vs. Non-Mediated Mode

To answer the first research question concerning the difference between the EFL intermediate learners' interpretation performance in translating texts from English to Persian on mediated mode versus non-mediated mode, the researcher conducted an ANCOVA analysis where the students' scores on the post-test in the experimental and control groups were compared while their scores on the pretest were taken as the covariate. The descriptive statistics showed that the mean score of the mediated group was almost three points higher than the non-mediated group.

Table 2. Mean and Standard Deviation of the Two Groups before Treatment

\begin{tabular}{llllll}
\hline & Group & $\mathrm{N}$ & Mean & Std. Deviation & Std. Error Mean \\
\hline Pre-test & non-mediated & 12 & $\mathbf{9 . 8 7}$ & $\mathbf{2 . 0 3}$ & .58 \\
& mediated & 12 & $\mathbf{9 . 2 0}$ & $\mathbf{1 . 5 5}$ & .44 \\
\hline
\end{tabular}


Table 3. Mean and Standard Deviation of the Two Groups after Treatment

\begin{tabular}{llllll}
\hline & Group & $\mathrm{N}$ & Mean & Std. Deviation & Std. Error Mean \\
\hline posttest & Non-mediated & 12 & $\mathbf{1 2 . 8 3}$ & $\mathbf{2 . 0 4}$ & .59 \\
& Mediated & 12 & $\mathbf{1 5 . 3 1}$ & $\mathbf{1 . 5 8}$ & .45 \\
\hline
\end{tabular}

The following Table shows Levene's Test of Equality of Error Variances.

Table 4. Levene's Test of Equality of Error Variances ${ }^{a}$

\begin{tabular}{llll}
\hline $\mathbf{F}$ & df1 & df2 & Sig. \\
\hline 2.604 & 1 & 22 & .121 \\
\hline
\end{tabular}

Tests the null hypothesis that the error variance of the dependent variable is equal across groups.

Design: Intercept + PRETEST + GRP

As the Table shows, the assumption of homogeneity of variances has not been violated $(\rho=.121)$ since the Sig. value is greater than .05. Thus, the required assumptions were met.

Table 5 indicates the results of the ANCOVA analysis.

Table 5. ANCOVA Analysis (Tests of between-Subjects Effects)

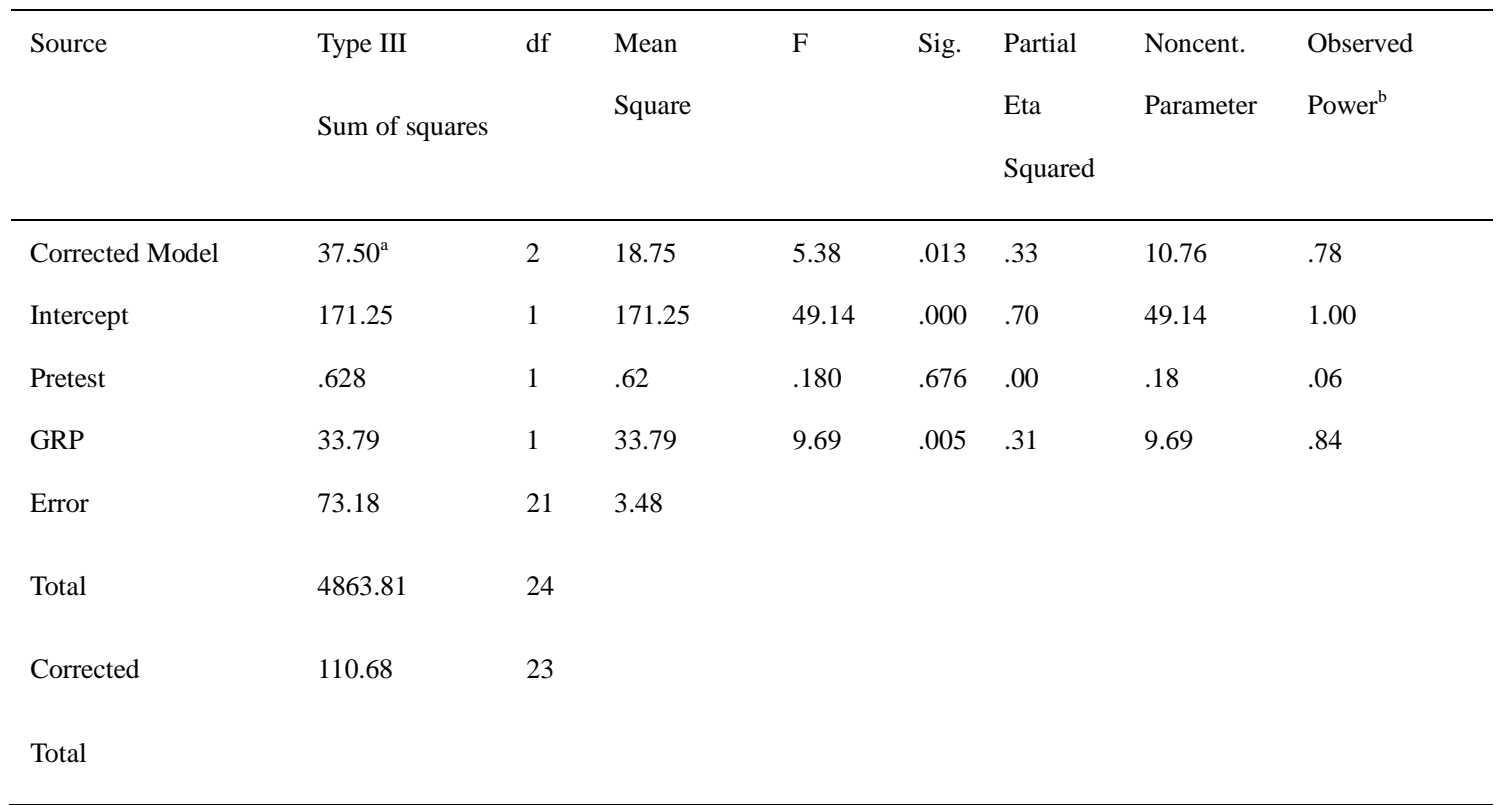

a. R Squared = .339 (Adjusted R Squared $=.276)$.

b. Computed using alpha $=.05$.

As it can be seen in this Table, after controlling for the pre-test scores, there was a significant difference among the two groups in interpretation ability, $\mathrm{F}(1,21)=9.69, \rho=.005$, partial eta $^{2}=.31$. Moreover, 
the power for them was high (observed power $=.84$ ). The effect size was also considered, as indicated by the corresponding partial eta squared value. The value in this case is . 31 which is a high effect size according to the interpretation of eta squared: .01= small effect, .06 = moderate effect and $.14=$ large effect.

7.2 Paired-Sample T-Test: The Difference between the Learners' Interpretation Performance in PeerMediated vs. Clip-Mediated Mode

In order to answer the second research question concerning the difference between the EFL intermediate learners' interpretation performance in translating texts from English to Persian on different kinds of mediation (clip-mediated vs. peer-mediated mode), a paired-sample T-test was conducted. As it was explained in the procedure, after the second session in the experimental group, the students' scores in the odd sessions were regarded as peer-mediated scores and their scores in even session showed clip-mediated scores. The following Table indicates the results:

Table 6. Paired Samples T-test

Paired Differences

Confidence Interval

of the differences

Sig.

\begin{tabular}{|c|c|c|c|c|c|c|c|c|c|}
\hline & & Mean & SD & SEM & Lower & Upper & $\mathrm{t}$ & $\mathrm{df}$ & (2-tailed) \\
\hline Pair & Clip-peer & -1.3125 & 1.378 & .39782 & -2.18 & -.43 & -3.29 & 11 & .007 \\
\hline
\end{tabular}

As the Table shows, the Sig. (2-tailed) value is less than .05 (.007), thus there is a significant difference in the mean scores on the dependent variable for different kinds of mediation. Accordingly, the second null hypothesis is also rejected and there is a significant difference between the EFL intermediate learners' interpretation performance in translating texts from English to Persian on clip-mediated versus peer-mediated mode. Meanwhile, the researcher checked the eta squared to estimate the effect size between the groups. SPSS does not provide this figure, but it can be computed by this formula:

Pallant: $\mathrm{t}^{2} / \mathrm{t}^{2}+(\mathrm{N} 1+\mathrm{N} 2-2)$

As the Table shows, in this study, $\mathrm{t}=3.29$. Therefore:

Eta squared $=(3.29)^{2} /(3.29)^{2}+(12+10)=10.82 / 32.82=0.32$

The usual interpretation of eta squared is:

01= small effect, $.06=$ moderate effect, and .14 = large effect

In this study, eta squared is .32 which means that the effect size is very large; indicating that peer-mediation improved the learners' interpretation far more than clip-mediation since the effect size was considerable. 


\subsection{Analysis of the Students'Attitudes Regarding the Efficacy of Mediation}

In order to analyze the participants 'reflection toward mediation and their listening comprehension performance, the researchers conducted a semi-structured interview with the students in experimental group. The interviewees answered the questions individually during 15-20 minutes while their voices were recorded to be transcribed later. With regard to the questions concerning the main factors affecting listening comprehension, all the interviewees answered that speed is the most important factor for listening comprehension skill. In other words, if a listener does not have the time needed for listening and comprehending the sentences, he / she will not able to comprehend that part. Thus, sufficient time should be allocated to each segment of the oral text so as to listen and understand it, otherwise, the scores do not show the listeners' listening comprehension ability. Most of the interviewees stated that the rate of speech, accent, and the density of the oral text were the most effective factors in listening comprehension, too. It was also found out that the existence of difficult problems in the text caused the learners not to pay attention to the remaining parts. Moreover, preparation before the listening task and having awareness about the topic could help the students to make inferences and suggest more acceptable translations.

With regard to the questions related to interpretation performance, the interviewees remarked note-taking and repetition (100\%) were the most effective strategies that helped them in translation process. Some also expressed that paraphrasing (41.6\%) helped them translate the sentences faster.

With regard to the respondents' attitudes toward different kinds of mediation, it was concluded that both kinds of mediation (clip mediation and peer-mediation) were helpful, but some believed that the extra audio VOA clip could not help them much; on the contrary, peer mediation was very helpful, because they could get the correct and final answer with the gradual help and hints of their peers as well as the teacher. They also expressed that mediation decreased their anxiety and caused them be more relaxed and comfortable, which in turn increased their self-confidence and helped them solve their interpretation problems better especially after peer mediation sessions.

\section{Discussion and Conclusion}

This study examined the EFL intermediate female learners' interpretation performance in translating texts from English into Persian on mediated vs. non-mediated mode as well as the different kinds of mediation mode (clip-mediated vs. peer-mediated).

There were similar studies examining the impact of mediation on different skills such as reading comprehension skill (Shabani, 2012), listening comprehension skill (Ableeva, 2010), and writing skill (Isavi, 2012). As the results of the present study indicate, mediation assisted learning can be a more effective mode of learning and the results of the study confirmed the findings of other studies (e.g., Gibbons, 2003; Poehner \& Lantolf, 2005), when they concluded that learners perform better when they are provided with mediation in joint activities. This finding is also echoed by Lidz (1995) who maintained that when learners are engaged in a joint activity, they can be very helpful and insightful not

Published by SCHOLINK INC. 
only to overcome the difficulty of the test, but also to reach the stage where they can construct meaning in an autonomous way, and use problem-solving strategies in learning process. Based on the findings of this study, it was indicated that there was a significant difference between the EFL intermediate female learners' interpretation performance in translating texts from English into Persian on mediated vs. non-mediated mode and also on different kinds of mediation mode (clip-mediated vs. peer-mediated). There are many factors affecting learners' interpretation performance in interpretation classes like linguistic, emotional, and listening comprehension skill, among which mediation can be an effective one. This highlights once again the effect of mediation as an independent variable on learning; since it can help the learners build up an independent learning behavior.

The research findings also revealed that between two kinds of mediation (clip-mediation and peer-mediation), the second one had more effect on increasing the learners' interpretation performance and the participants' scores had improved more through this kind of mediation. Although the results of the students' tests after clip mediation showed its positive effect on the learners' performance, peer mediation was more effective according to the students' scores and their answers to the interview questions. DA can help the learners build up an independent learning behavior.

With regard to the students' emotional reaction and attitudes to mediation, the analysis of the participants' responses during semi-structured interview revealed that both kinds of mediation had a positive effect on the learners' performance. The interviewees remarked that they were active during mediation sessions and their improved performance caused them act better in the next quizzes. All participants agreed that their improvement in the post-test has been the result of the mediation, whether clip-mediation or peer-mediation, and stated that their self-confidence and autonomy increased which in turn increased the use of problem solving strategies through interaction. Meanwhile, they asserted that the most frequent strategies during their interpretation performance were note-taking, repetition, and paraphrasing.

This study showed that dynamic assessment can be efficient in interpretation fields, like its efficiency in other fields. It confirmed that different learners with different ZPDs require different levels of assistance. Using dynamic assessment approaches in teaching interpretation courses can entail better results for both instructors and students in comparison to the traditional methods. The students can gain better scores in their tests and have less amount of anxiety during their assessment through group working by interacting effectively with their peers and with their instructor. DA improves their function gradually and gives them motivation to solve more difficult problems. The instructors, on the other hand, can recognize the students' problems easier and help them in various degrees and according to their Zone of Proximal Development (ZPD); this gives them opportunities to be good problem solvers and self-confident persons in their life.

\section{References}

Ableeva, R. (2010). Dynamic assessment of listening comprehension in second language learning Published by SCHOLINK INC. 
(Unpublished doctoral dissertation). The Pennsylvania State University.

Alavi, S. M., Kaivanpanah, S. H., \& Shabani, K. (2012). Group dynamic assessment: An inventory of Mediationl strategies for teaching listening. The Journal of Teaching Language Skilss, 3(4), 27-58.

Aljaafreh, A., \& Lantolf, J. P. (1994). Negative feedback as regulation and second language learning in the zone of proximal development. The Modern Language Journal, 78, 463-483. https://doi.org/10.1111/j.1540-4781.1994.tb02064.x

Angelelli, C. V., \& Jacobson, H. E. (2009). Testing and assessment in translation and interpreting studies. Amsterdam/Philadelphia: John Benjamin’s Publishing Company. https://doi.org/10.1075/ata.xiv

Baek, S. G., \& Kim, K. J. (2009). The effect of dynamic assessment based instruction on children’s learning. Asia Pacific Education Review, 4(2), 189-198. https://doi.org/10.1007/BF03025361

Brown, H. D. (2001). Teaching by principles: An interactive approach to language pedagogy (2nd ed.). White Plains, New York: Longman.

Davies, M. G. (2004). Multiple voices in the translation classroom. Amsterdam/Philadelphia: John Benjamin’s Publishing Company. https://doi.org/10.1075/btl.54

Dornyei, Z. (2007). Research methods in applied lingyistics. Oxford: Oxford University Press.

Fahmy, M. M. (2013). The effect of dynamic assessment on adult learners of arabic: A mixed-method study at the defense language institute foreign languagecenter (Doctoral dissertation). Retrieved from http://repository.usfca.edu/diss.

Flanagan, D., Mascolo, J., \& Hardy-Braz, S. (2009). Quality of standardized testing instruments. Retrieved from http://www.education.com/reference/article/standardized-testing/

Fowler, W. S., \& Coe, N. (1976). Nelson english language tests. London: Butler \& Tanner Ltd.

Gibbons, P. (2003). Mediating language learning: Teacher interactions with ESL students in a content-based classroom. TESOL Quarterly, 37(2), 247-273. https://doi.org/10.2307/3588504

Gile, D. (1992). Basic theoretical components in interpreter and translator training. In C. Dollerup, \& A. Loddegaard (Eds.), Teaching translation and interpreting: Training talent and experience (pp. 185-344). John Benjamin’s, Amsterdam/Philadelphia. https://doi.org/10.1075/z.56.29gil

Goh, C. C. M. (2000). A cognitive perspective on language learners' listening comprehension problems. System, 28, 55-75. $\quad$ Retrieved from http://www.finchpark.com/courses/grad-dissert/articles/listening/listening-comprehension-problem s.pdf. https://doi.org/10.1016/S0346-251X(99)00060-3

Hamouda, A. (2013). An investigation of listening comprehension problems encountered by Saudi students in the EL listening classroom. International Journal of Academic Research in Progressive and Development, 2(2), 113-155.

Haywood, H. C., \& Lidz, C. S. (2007). Dynamic assessment in practice, clinical and educational applications. Retrieved from http://www. Cambridge.org/9780521849357.

Haywood, H. C., \& Tzuriel, D. (Eds.) (1992). Interactive assessment. New York: Springer-Verlag. 
Isavi, E. (2012). The effect of dynamic assessment on Iranian L2 writing performance. https://doi.org/10.1007/978-1-4612-4392-2

Johnson, K. E. (2009). Second language teacher education a sociocultural perspective. New York and London: Routledge.

Kozulin, A., \& Garb, E. (2002). Dynamic assessment of EFL text comprehension of atrisk students. School Psychology International, 23, 112-127. https://doi.org/10.1177/0143034302023001733

Lantolf, J. P., \& Poehner, M. E. (2004). Dynamic assessment of L2 development: Bringing the past to the future. Journal of Applied Linguistics, 1(1) , 49-72. https://doi.org/10.1558/japl.1.1.49.55872

Lantolf, J. P., \& Poehner, M. E. (2008). Dynamic assessment. In E. Shohamy (Eds.), The encyclopedia of language and education: Language testing and assessment (pp. 273-285). Cambridge: Cambridge University Press. https://doi.org/10.1007/978-0-387-30424-3_181

Lauchlan, F., \& Carrigan, D. (2013). Improving learning through dynamic assessment: A practical classroom resource for educational psychologists. London: Jessica Kingsley Publishers.

Lidz, C. S. (1995). Dynamic assessment and the legacy of L.S. Vygotsky. School Psychology International, 16, 143-153. https://doi.org/10.1177/0143034395162005

Lidz, C. S. (Ed.). (1987). Dynamic assessment: An interactional approach to evaluating learning potential. New York: Guilford. https://doi.org/10.1044/0161-1461.2704.367

Lidz, C. S., \& Pena, E. D. (1996). Dynamic assessment: The model, its relevance as a nonbiased approach, and its application to Latino American preschool children. Language, Speech, and Hearing Services in Schools, 27, 367-384. https://doi.org/10.1044/0161-1461.2704.367

Mayberry, M. D. S. (2006). Listening comprehension in the foreign language classroom: The cognitive receptive processes in the development of Spanish phonological perception (Doctoral dissertation). Retrieved from http://www.lib.utexas.edu/etd/d/2006/mayberrym78911/mayberrym78911.pdf

McLuhan, M. (1964). Understanding media. New York: McGraw-Hill.

Missiuna, C. (1987). Dynamic assessment: A model for broadening assessment in occupational therapy. $\begin{array}{llll}\text { Canadian Journal of } & \text { Occupational Therapy, }\end{array}$ https://doi.org/10.1177/000841748705400105

Munday, J. (2008). Introducing translation studies:theories and applications (2nd ed.). London and New York: Routledge.

Naeini, J. (2014). On the study of DA and SLA: Feuerstein's MLE and EFL learner's reading comprehension. Procedia-Social and Behavioral Sciences, 98, 1297-1306. https://doi.org/10.1016/j.sbspro.2014.03.546

Nord, C. (1997). Translating as a purposeful activity: Functional approaches explained. Manchester: St. Jerome.

Poehner, M. E. (2005) Dynamic assessment of oral proficiency among advanced L2 learners of French (Unpublished doctoral manuscript). The Pennsylvania State University.

Poehner, M. E. (2008). Dynamic assessment a vygotskian approach to understanding and promoting L2 Published by SCHOLINK INC. 
development. Berlin: Springer Publishing.

Poehner, M. E., \& Lantolf, J. P. (2005). Dynamic assessment in the language classroom. Language Teaching Research, 9(3), 233-265. https://doi.org/10.1191/1362168805lr166oa

Poehner, M. E., \& Lantolf, J. P. (2013). Bringing the ZPD into equation: Capturing L2 development during computerized. Dynamic Assessment. Language Teaching Research, 17(3), 323-342. https://doi.org/10.1177/1362168813482935

Richards, J. C., Hull, J., \& Proctor, S. (2005). New interchange 3 (3rd ed.). Edinburgh, Cambridge, UK: Cambridge University Press.

Sevignon, S. J. (1983). Communicative competence: Theory and classroom practice: Texts and contexts in second language learning. Addison-Wesley.

Shabani, K. (2012). Dynamic assessment of L2 learners' reading comprehension processes: A vygotskian perspective. Procedia-Social and Behavioral Sciences, 32, 321-328. https://doi.org/10.1016/j.sbspro.2012.01.047

Sternberg, R. J., \& Grigorenko, E. L. (2002). Dynamic testing: The nature and measurement of learning potential. New York: Cambridge University Press.

Sundersingh, J. (2001). Audio-based translation: Communicating biblical scriptures to non-literate people. Domeseries, 2.

Tzuriel, D. (2000). Dynamic assessment of young children: Educational and intervention perspectives. Educational Psychology Review, 12(4), 385-435. https://doi.org/10.1023/A:1009032414088

Tzuriel, D., \& Shamir, A. (2002). The effects of mediation in computer assisted dynamic assessment. $\begin{array}{lllll}\text { Journal of } & \text { Computer }\end{array}$ https://doi.org/10.1046/j.0266-4909.2001.00204.x

Venuti, L. (Ed.). (2000). The translation studies reader. London and New York: Routledge. https://doi.org/10.4324/9780203446621

Vygotsky, L. S. (1978). Mind in society. Cambridge, MA: Harvard University Press.

Yousif, A. A. (2006). Listening comprehension difficulties as perceived by. Lang. \& Transl., 19, 35-47.

\section{Appendix}

\section{Appendix I: Semi-structured interview questions}

1. What are the main factors influencing your listening comprehension ability?

2. Which factors can help the translation of oral clips?

3. What factors make the translation of oral texts difficult for you?

4. Did you have more problems in getting the sentences or in translating them?

5. Do you think that providing mediation can help improve your oral translation performance?

6. Which one do you think is more beneficial: clip mediation or peer mediation?

7. How can clip mediation help your oral translation?

8. How can peer mediation help your oral translation?

Published by SCHOLINK INC. 
9. What mediation techniques distinguish them from the common traditional techniques used in oral translation?

10. How did you feel through sessions including mediation?

11. Which one do you prefer the most: mediated or non-mediated sessions?

12. Is there anything else that you want to say about mediation and the sessions that you have experienced?

Appendix II: Meaning-Oriented Assessment Criteria (Kim's Rubric)

\begin{tabular}{|c|c|c|c|c|c|}
\hline & & & Lexis & Clause & Text \\
\hline \multirow[t]{8}{*}{ Major } & Experiential & Accuracy & $1-2$ pts & $2-3$ pts & \\
\hline & & Naturalness & $1-2$ pts & $2-3$ pts & \\
\hline & Logical & Accuracy & & $1-3$ pts & \\
\hline & & Naturalness & & $1-3$ pts & \\
\hline & Interpersonal & Accuracy & $1-2$ pts & & $3-5$ pts \\
\hline & & Naturalness & $1-2$ pts & & $3-5$ pts \\
\hline & Textual & Accuracy & & $1-2$ pts & $3-5$ pts \\
\hline & & Naturalness & & $1-2$ pts & $3-5 \mathrm{pts}$ \\
\hline
\end{tabular}

Minor Graphological mistakes such as spelling

0.5

Minor grammar mistakes that do not impact meaning

0.5 